\title{
ANALYSIS OF PIG PROFILES ON SMALL-SCALE PIG FARMERS IN MANOKWARI-WEST PAPUA
}

\author{
D. A. Iyai, B.W. I. Rahayu, I. Sumpe and D. Saragih \\ Faculty of Animal Sciences Fisheries and Marine Sciences, The State University of Papua, \\ Jl. Gunung Salju, Amban. Manokwari. Papua Barat 98314 - Indonesia \\ Corresponding E-mail: da.iyai@yahoo.com \\ Received January 16, 2011; Accepted July 18, 2011
}

\begin{abstract}
This study was aimed to determine the profiles of pig farming systems. Participatory situation analysis was employed to gain data relating to pig profiles in the urban and rural areas of Manokwari. Due to the interests of combining many correlated data, multivariate analysis using Principal Component Analysis (PCA) was performed. Cluster Analysis using Agglomerative Hierarchical Clustering was applied for analysis of merge samples based on similarity in components' composition across sites. There were various twelve classes of pig profiles in Manokwari. In principal component of the first axis correlation of several components shows strong positive relation e.g. in piglets, sows, and total herd size. Status of region in the first axis of PCA (P1) through which pigs were raised had negative correlation, including grower, household member and pig production. In the second axis (P2), negative correlations were shown in piglets, grower, boars, total herd size and the Pig Production Potential (PPP). Status of region has underpinned profiles of pigs. Several farmers were able to manage their farm continuity in a steady composition. Selling pigs was the main aim and few farmers play a role as pure breeder.

Keywords: agglomerative hierarchical clustering, pig profiles, principal component analysis, cluster analysis
\end{abstract}

\section{INTRODUCTION}

In general, there are four pig keeping systems in Manokwari, West Papua (Iyai, 2008). Most of them are small-scale systems. Using local resources, such as feeds, housing materials, and pig breeds, Papuan pig farmers really depend on this mean of livelihood. There are many variations in keeping systems and locations in uses, such as scavenging, restrained, semi-intensive and penned systems and urban-rural pigs.

Inputs such as herd sizes, sex ratio and physiological ages will determine the profiles and performances of a farm. One of the on-farm components agreement can be encountered for animals, such as piglets (Moore et al., 2005), weaned piglets (Taveros and Moore, 2001), grower (Lee et al., 2005) and mature pigs, i.e. gilts, sows and boars (Lanada et al., 2005). Under small-scale pig farming systems, pigs are widely raised and distributed in a large number of households without a well-prepared breeding program. The local technical department does not have program in improving genetic quality of pigs. Information of pig composition should be compiled and become a worthwhile baseline information for phenotypic and genetic resource improvements (Hall, 1989), annual productivity particularly the sows (Lanada et al., 2005), pig production and pig production efficiency (Chiduwa et al., 2008). This information is useful in pig keeping management. Profile of pigs could tell the farmers what the trend of herd size prone will be, population growth and other productivity measurements. By doing this, farmers will care about their farming sustainability (Gaspar et al., 2007) and increase income sources. Due to many baseline information, farmers have to consider many components in deriving conclusion and action to be done. Therefore, this research was aimed to study the profiles of pigs that were shaping pig farming systems in Manokwari.

\section{MATERIALS AND METHODS}

\section{Sites and Respondents}

A field studies was carried out in Manokwari regency (Iyai, 2008), comprised of six districts, i.e. Northern Manokwari district, Eastern Manokari District, Western Manokwari district, 
Warmare district, Prafi district and Masni district. Fifty (50) farmers as the respondents were interviewed to describetheir pig farming system (Table 1). Pig farming system were categorized into four pig keeping systems that were based on the inputs process in farming activities, boundaries and output.

Participatory situation analysis (PSA) was employed to approach pig farmers (Conroy, 2005). Interviews using questionnaire were done to collect information concerning pig profiles from 50 pig farmers. A number of 355 pigs comprised of 106 piglets, 74 weaned piglets, 103 growers, 72 sows and 28 boars were observed and counted in every sample farmer. Due to this nonparametric and multivariate data, i.e. categorical data, data analysis using principal component analysis (PCA) was applied (Harris, 2001). It was assumed that the components had linear correlation and had gradient less than 3. PCA helped in depicting relational parameters, seeking un-correlating between parameters and graphing two and three dimensional graphics. Prior to PCA, cluster analysis (CA) using Agglomerative Hierarchical Clustering (AHC) was used to classify similarity and dissimilarity amongst groups of variables into a tree diagram. In Principal component analysis (PCA), nine factors related to pig profiles in the two regions, i.e. urban and rural in Manokwari.

\section{Variables}

Variables were piglets, weaned piglets, growers, sows, boars, herd sizes, regional status (urban vs rural), household member (Hh), and pig production potential (PPP). Quantification data was done only for The PPP, i.e. an indicator of pig production systems (Chiduwa, et al., 2008). The PPP was calculated as $\mathrm{PPP}=\{(\mathrm{M} / \mathrm{PPE}) \times 100\}$, where $M$ was number of growers and mature pigs consumed and/or sold. Pig production efficiency (PPE) was computed as PPE $=$ (sum of weaning piglets, grower, sows and boars)/total herd.

\section{Data Analysis}

The PCA was applied to find correlation of factors. Data were analyzed using software of Xlstat (2009). A multivariate analysis (MVA), i.e. principal component analysis (Ho, 2006) was performed to understand the correlation between factors. Agglomerative hierarchical clustering (AHC) was used to classify constraints in similarity classes.

\section{RESULTS AND DISCUSSION}

\section{Agglomerative Hierarchical Analysis of Pig Profiles}

Figure 1 shows a Agglomerative Hierarchical Clustering (AHC) resulted in a binary clustering tree diagram (dendogram). Dendogram is a graph explaining progressive of the data. By knowing this it is possible to gain an idea of a suitable number of classes in which data can be classified. Agglomeration using Unweighted pair-group (UWPG) average linkage is a good compromise between the two preceding criteria, and provides a fair representation of the data space properties. In using Agglomerative Hierarchical Principal (Davidson and Ravi, 2005), clustering is done commenced at the individual/or observation sample data. This is apparently on the contrary with divisive techniques, e.g. TWINSPAN analysis (Braak et al., 2003). In TWINSPAN, clustering is begun with all samples (sites) in one cluster divided this into more clusters. In cluster analysis it could reduce complex data set, identify patterns in data set by identifying clusters of observation and components. Added to this and more important is

Table 1. Respondents' Characteristic

\begin{tabular}{|c|c|c|c|}
\hline No. & Pig Keeping Systems & Respondents (Observants) & Total Sample (n) \\
\hline 1. & Free-range pig keeping & $\begin{array}{l}\text { Obs17, Obs18, Obs32, Obs33, Obs34, Obs35, } \\
\text { Obs36, Obs37, Obs38, Obs39, Obs44, Obs } 45 \text {, } \\
\text { Obs46, Obs47, Obs48, Obs49, Obs50 }\end{array}$ & 17 \\
\hline 2. & Restrained pig keeping & Obs21, Obs22, Obs24, Obs25, Obs27, Obs 28 & 6 \\
\hline 3. & $\begin{array}{l}\text { Semi-penned pig } \\
\text { keeping }\end{array}$ & $\begin{array}{l}\text { Obs1, Obs2, Obs3, Obs4, Obs5, Obs6, Obs7, Obs8, } \\
\text { Obs9, Obs12, Obs15, Obs29, Obs30, Obs31, } \\
\text { Obs } 40, \text { Obs } 43\end{array}$ & 16 \\
\hline 4. & Penned pig keeping & $\begin{array}{l}\text { Obs10, Obs11, Obs13, Obs14, Obs16, Obs19, } \\
\text { Obs20, Obs23, Obs26, Obs41, Obs42 }\end{array}$ & 11 \\
\hline
\end{tabular}




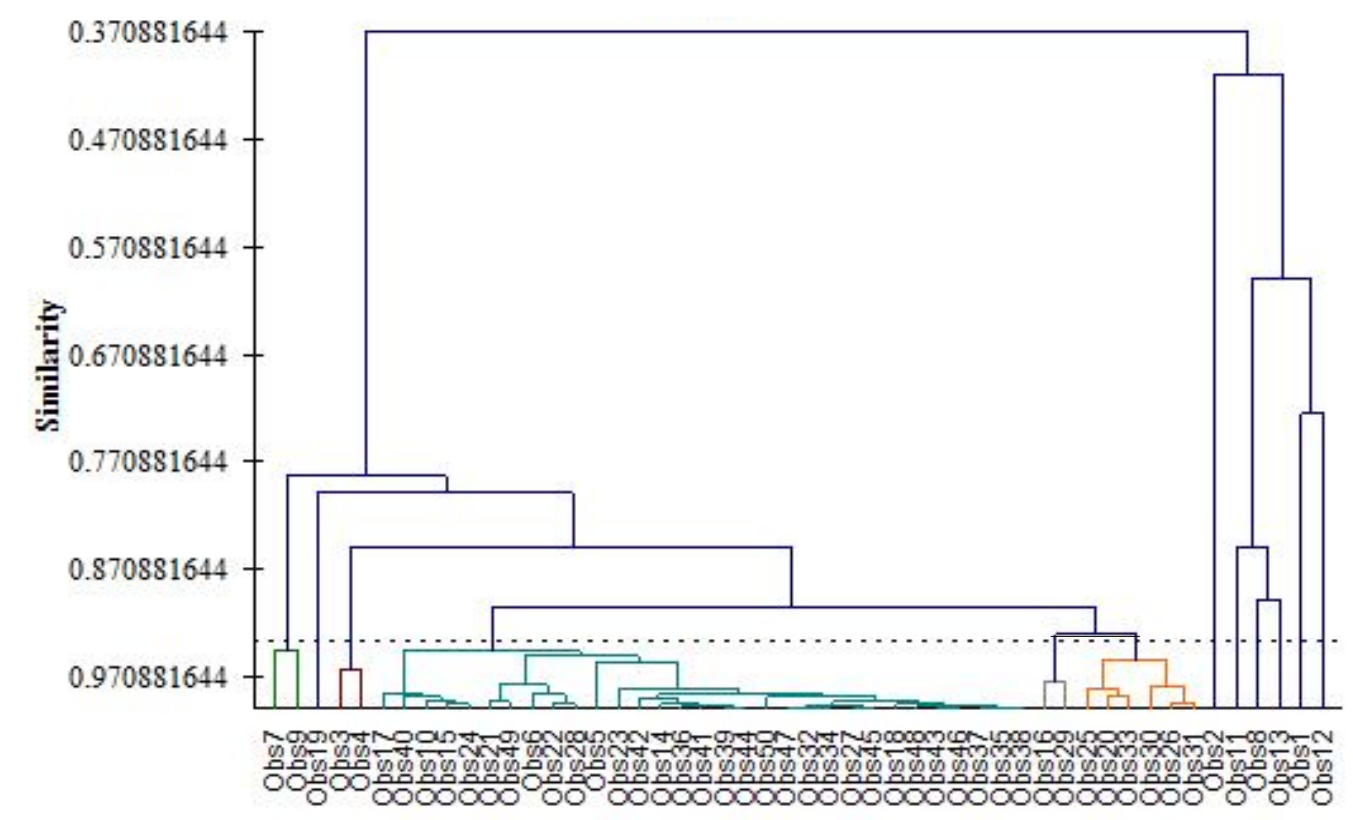

Figure 1. A binary tree diagram categorized based on physiological ages of pigs in Manokwari. The dotted-line shows truncation.

to generate hypotheses on interactions between observation and components in the field of animal agriculture. Figure 1 shows that $>80 \%$ of all observations shaping these three classes had high similarity. The progressing of similarity decreases simultaneously up to 0.37 or $37 \%$.

Of these four pig keeping systems (Iyai, 2008), it is proven that profiles of pig keeping systems based on physiological ages of pigs raised under small-scale systems sometimes are vary. Herd size and pig profiles were independently changeable. No rules were made in shaping certain herd size in certain pig keeping systems.

It should have rather clear information with respect to pig profiles and other related components (Figure 2). Distribution of observations, i.e. pig farmers around diagram tree (binary diagram) had implication in shaping of pig profiles in urban and rural pig farmers. What motivations are involved to shape pig profile should be originated from pig farmers' decision, available local resources and inhibiting factors (Wabacha et al., 2004). Iyai (2008) identified several decisions made, available local resources and constraints as inhibiting factors.

The finding of this cluster analysis (CA) were that there were 12 classes in grouping physiological ages of pigs under the studied four pig keeping systems (Iyai, 2008). Class (C)1, class 2, class 6 , class 7, class 8 , class 9 , and class 11 had only 1 observant, i.e. subsequently Obs1, Obs2, Obs8, Obs11, Obs12, Obs13, and Obs19, mostly were in urban areas (Table 2). When a classes had 1 observation, it is clumsy to use a dissimilarity table. Pig herd size and physiological ages may have similar role in categorizing development of pig farming systems.

Classes having observations between 2 up to 6 numbers were Class 3, class 10 and class 12. This finding was found in rural areas. The rest was class 4 which had 31 observations. Similar classes were found closely related between $\mathrm{C} 10$ $\mathrm{C} 12$, C6-C9, and $\mathrm{C} 1-\mathrm{C} 8$, while dissimilarity cases were found not closely related between $\mathrm{C} 1-\mathrm{C} 8$ versus $\mathrm{C} 10-\mathrm{C} 12$ and so forth. Those classes shown in observations revealed that no boundaries had had by location, i.e. urban and rural pig farming. The phenomenon of pig profile in Manokwari was interchangeable, but profiles of physiological ages in pig keeping systems both in urban and rural were slightly similar.

The implication of this research showed that under small-scale pig production systems, physiology ages of pigs had high diversity (Table 2). Raising pigs under modern intensive keeping or in sub tropical countries such as in Europe have population or herd size based on household resources. Added to this regulation that is binding every farmer to efficiently raise their pigs. 


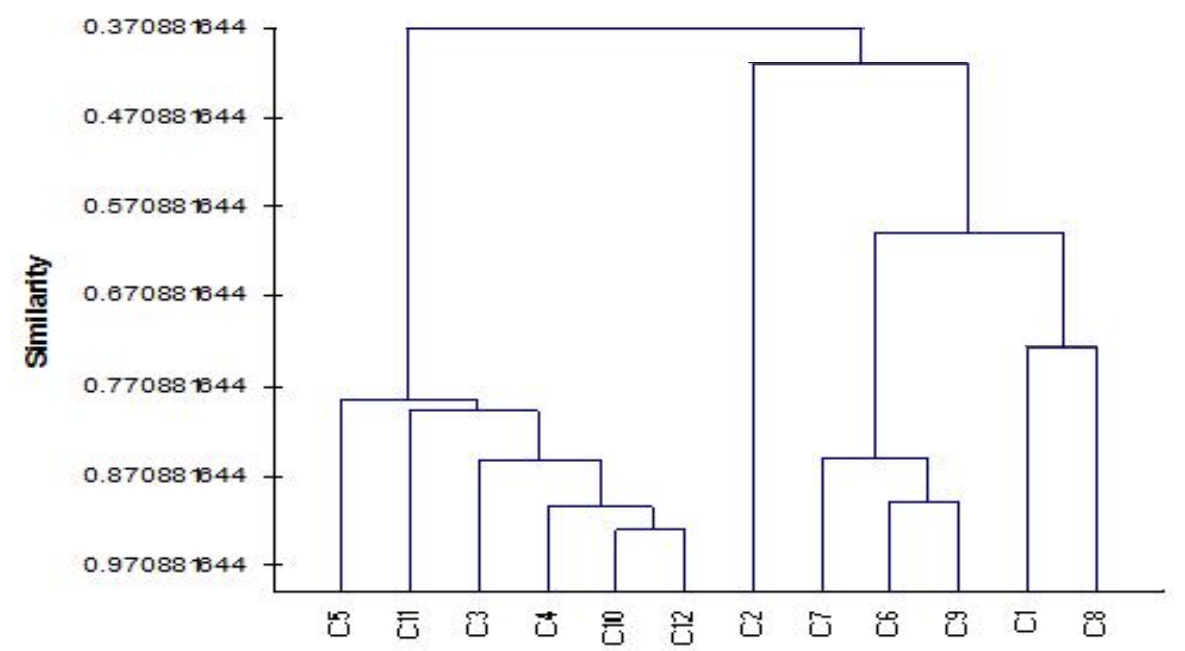

Figure 2. Summary of AHC of Physiology Ages of Pigs in Manokwari

Table 2. Classes, Observations and Classification based on Physiological Ages of Pigs.

\begin{tabular}{|c|c|c|c|}
\hline Class & Respondents (Observants) & Pig keeping systems & Frequency \\
\hline Class 1 & Obs1 & Semi-penned & 1 \\
\hline Class 2 & Obs2 & Semi-penned & 1 \\
\hline Class 3 & Obs3,Obs4 & Semi-penned & 2 \\
\hline Class 4 & $\begin{array}{l}\text { Obs5, Obs6, Obs10, Obs 14, Obs15, Obs 17, Obs18, } \\
\text { Obs21, Obs22, Obs23, Obs24, Obs27, Obs28 } \\
\text { Obs32, Obs34, Obs35, Obs36, Obs37, Obs38, } \\
\text { Obs39, Obs40, Obs41, Obs42, Obs43, Obs44, } \\
\text { Obs45, Obs46, Obs47, Obs48, Obs49, Obs50 }\end{array}$ & $\begin{array}{c}\text { Free-range, } \\
\text { Semi-penned, } \\
\text { Restrained and } \\
\text { Penned pig keeping systems }\end{array}$ & 31 \\
\hline Class 5 & Obs7,Obs 9 & Semi-penned & 2 \\
\hline Class 6 & Obs8 & Semi-penned & 1 \\
\hline Class 7 & Obs11 & Penned & 1 \\
\hline Class 8 & Obs12 & Semi-penned & 1 \\
\hline Class 9 & Obs13 & Penned & 1 \\
\hline Class 10 & Obs 16, Obs 29 & Penned and Semi-penned & 2 \\
\hline Class 11 & Obs19 & Penned & 1 \\
\hline Class 12 & Obs20,Obs25,Obs26,Obs30,Obs31,Obs33 & $\begin{array}{l}\text { Penned, restrained, semi- } \\
\text { penned, free-ranges }\end{array}$ & 6 \\
\hline
\end{tabular}

Distribution of Pig Profiles in Principal Component Analysis (PCA)

Eigenvalue/lambda $(\boldsymbol{\lambda})$ is used to measure the fraction of variation explained in the data set (Ho, 2006; Smith, 2002). The proportion of the variance is merely the Eigenvalue for that axis divided by the total variance, i.e. the sum of the diagonal of the cross-product matrix. Other Eigenvalues and variability combinations were under these two combinations. Eigenvalue/lambda and percentage variance (variability) of the P1 axis of PCA was slightly low (33.29\%). By adding the second component or/ second axis (P2), total cumulative variance was $54.93 \%$. The remains were $\mathrm{P} 3, \mathrm{P} 4, \mathrm{P} 5, \mathrm{P} 6, \mathrm{P} 7$ and $\mathrm{P} 8$ contributing into small percentage number, i.e. $14.2 \%, 12.1 \%, 10.6 \%, 4.5 \%, 2 \%$ and $1.5 \%$, respectively.

The values of Eigenvectors (Smith, 2002) contain a set of scores that shows the weight of each variable, i.e. components on each axis of PCA. The eigenvectors vary between -1 to +1 . 
Variables of factors drawn from pig farmers are shown in Table 3. Values of Eigenvectors in particular P1 were severe positive weighting.

\section{Correlations between Variables and Factors in Pig Profile Components}

Figure 4 shows correlation between vaiable and factor of technical and non-technical pig farming system in Manokwari. Status of region in the first axis (P1) through which pigs were raised had no correlation $(\mathrm{r}=-0.051)$, as well as grower $(\mathrm{r}=-0.096)$, household member $(\mathrm{r}=-0.041)$ and pig production ppotential $(\mathrm{r}=-0.693)$. In the other component of the first axis, piglets $(r=0.905)$, sows $(r=0.723)$, total herd size $(r=0.933)$ had positive correlation. It can be seen in the Table 2 and Figure 2, the total cumulative of axes showing correlation was $54.93 \%$. In the second axis (P2), negative correlations were shown in piglets $(r=0.007)$, grower $(r=0.077)$, boars $(r=-$ $0.332)$, total herd size $(\mathrm{r}=-0.049)$ and the PPP $(\mathrm{r}=-$ 0.1225). Several components had low correlations, i.e. weaned piglets and sows. Figure 4 could position this numbers in quadrant $\mathrm{I}$.

In the PCA analysis, there were more or less four distinctive groups of plots, those are quadrant

Table 3. Principal Component Analysis, Eigenvalue, Cumulative Variance and Eigenvectors of Physiological Ages of Pigs in Manokwari

\begin{tabular}{lrrrrrrrr}
\hline & P1 & P2 & P3 & P4 & P5 & P6 & P7 & \multicolumn{1}{c}{ P8 } \\
\hline Eigenvalue & 2.997 & 1.947 & 1.277 & 1.087 & 0.958 & 0.404 & 0.193 & 0.137 \\
Variability, \% & 33.298 & 21.631 & 14.194 & 12.081 & 10.641 & 4.493 & 2.141 & 1.521 \\
Cumulative, \% & 33.298 & 54.929 & 69.123 & 81.203 & 91.845 & 96.338 & 98.479 & 100.000 \\
& & & & & & & & \\
Eigenvectors: & & & & & & & & \\
Status region & -0.029 & 0.674 & -0.078 & 0.113 & -0.015 & -0.261 & 0.070 & -0.673 \\
Piglets & 0.523 & -0.005 & 0.267 & -0.119 & -0.054 & 0.031 & 0.610 & -0.026 \\
Weaned & 0.283 & 0.003 & -0.300 & -0.189 & 0.768 & -0.253 & -0.276 & 0.046 \\
Grower & -0.056 & -0.055 & 0.559 & 0.690 & 0.234 & 0.026 & -0.273 & -0.044 \\
Sows & 0.418 & 0.115 & -0.368 & 0.178 & -0.203 & 0.666 & -0.349 & -0.120 \\
Boars & 0.130 & -0.238 & -0.520 & 0.539 & -0.279 & -0.495 & 0.128 & 0.118 \\
Total herd size & 0.539 & -0.035 & 0.129 & 0.223 & 0.217 & 0.008 & 0.176 & -0.025 \\
Hh & -0.023 & 0.681 & -0.028 & 0.147 & 0.034 & 0.031 & 0.098 & 0.709 \\
PPP & -0.400 & -0.089 & -0.312 & 0.259 & 0.430 & 0.421 & 0.542 & -0.108 \\
\hline
\end{tabular}

Table 4. Correlation between Variables and Factors of Technical and Non-technical Pig Farming Systems in Manokwari

\begin{tabular}{lrrrrrrrr}
\hline & \multicolumn{7}{c}{ Correlations between Variables and Factors } \\
\cline { 2 - 9 } & \multicolumn{1}{c}{$\mathrm{r}_{\mathrm{P} 1}$} & \multicolumn{1}{c}{$\mathrm{r}_{\mathrm{P} 2}$} & \multicolumn{1}{c}{$\mathrm{r}_{\mathrm{P} 3}$} & \multicolumn{1}{c}{$\mathrm{r}_{\mathrm{P} 4}$} & \multicolumn{1}{c}{$\mathrm{r}_{\mathrm{P} 5}$} & $\mathrm{r}_{\mathrm{P} 6}$ & $\mathrm{r}_{\mathrm{P} 7}$ & \multicolumn{1}{c}{$\mathrm{r}_{\mathrm{P} 8}$} \\
\hline Status region & -0.051 & 0.941 & -0.088 & 0.118 & -0.014 & -0.166 & 0.031 & -0.249 \\
Piglets & 0.905 & -0.007 & 0.301 & -0.124 & -0.053 & 0.020 & 0.268 & -0.010 \\
Weaned & 0.491 & 0.004 & -0.339 & -0.197 & 0.751 & -0.161 & -0.121 & 0.017 \\
Grower & -0.096 & -0.077 & 0.632 & 0.720 & 0.229 & 0.017 & -0.120 & -0.016 \\
Sows & 0.723 & 0.161 & -0.415 & 0.186 & -0.199 & 0.424 & -0.153 & -0.044 \\
Boars & 0.224 & -0.332 & -0.587 & 0.562 & -0.273 & -0.314 & 0.056 & 0.044 \\
Total herd size & 0.933 & -0.049 & 0.146 & 0.233 & 0.213 & 0.005 & 0.077 & -0.009 \\
Hh & -0.041 & 0.950 & -0.032 & 0.153 & 0.034 & 0.020 & 0.043 & 0.262 \\
PPP & -0.693 & -0.125 & -0.353 & 0.270 & 0.421 & 0.267 & 0.238 & -0.040 \\
\hline
\end{tabular}




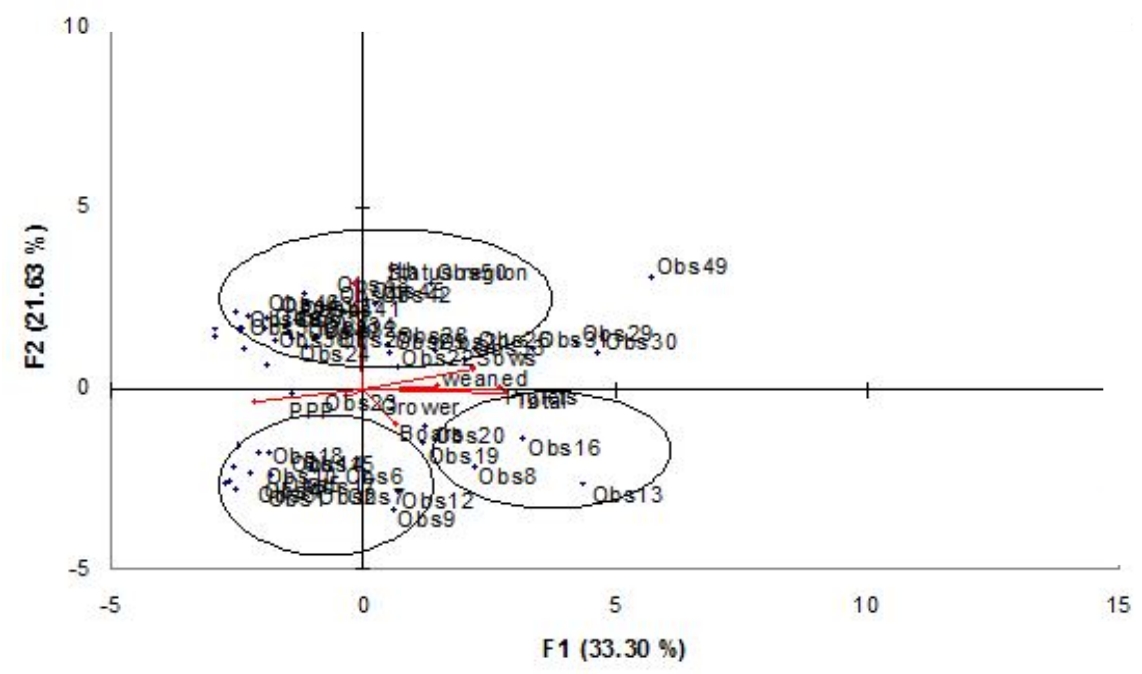

Figure 4. Distribution of Observations and Components in the Two-First Principal Component Analysis Axes

I, II, III and IV. Components at the right angles are independent of one another. In the quadrant I several observations were close and dispersed near sows and weaned piglets' ages. Weaned piglets and sows were independent with piglet, total herd size and boars. Weaned piglets and sows were not associated with PPP and grower.

In quadrant II, several observations were slightly far and had weak relationship of PPP and grower. In quadrant III, status of region was not associated with boars, piglets and total herd size. Status of region was independent with PPP and grower. In quadrant III status of region had many observation dispersed closed to it. Status of region was not associated with boars, piglets and total herd size. However, status of boars' fertility (semen and its reproduction parameters) should become the first priority (Smital, 2009). In quadrant IV, few observations were closely to piglets, total herd size and boars. A such in quadrant II, these components in quadrant IV had not associated with quadrant II. Observation 11 had weak relationships with components in quadrant IV.

The implication of this finding is that status of region has strong profiles of pigs, in particular with sows and weaned piglets. Unweaned piglets (Moore et al., 2005) also occur in these pig keeping systems.

Sows as grouped in the first quadrant shown strong relations with weaned piglets. A high quality genetic of sow will produce in average higher number of piglets and post weaned individual pigs after that. Despite the fact that, Iyai (2008) finding was quite low of produced piglet and weaned piglets in Manokwari compared to Nepal (Gatenby and Chemjong, 1992), Vietnam (Lemke et al., 2008; Peters et al., 2006), India (Deka et al., 2007), Thailand (Nakai, 2008) and Philippines (Lanada et al., 2005).

Sow and weaned piglet associate with boars (Gatenby and Chemjong, 1992) and therefore producing high number of litter size become important. A high quality of boars will as well determining pig production productivity in Manokwari. However, it seems that due to high number of inbreeding genetic quality of boars in Manokwari should be improved quite a lot.

\section{CONCLUSION}

Based on pig physiological ages, profiles of pig farmers can be grouped into twelve classes. Under small-scale pig production systems, physiological ages of pigs had high diversity. Pig herd size and physiological ages may have similar role in categorizing development of pig farming systems. Piglets number, sows and total herd size have mutual indicators for development of pig farming systems in Manokwari. Status of regions, growers household member, and PPP have low indicator for pig farming development. The implication of this finding is that status of region has underpinned profiles of pigs, in particular 
with sows and weaned piglets. Small number of farmers could maintain and manage their farm continuity in a steady composition of pig profiles.

\section{ACKNOWLEDGMENT}

This research was done under financial support of NUFFIC-NESO scholarship programs and Wageningen University -DLO, The Netherlands. Special thanks are given due to helps of Stafanus Korwa, Ir. Wellem Jantewo, Ir. Agustinus Idie, Ir. Ari Hindom and farmers collaboration during collecting data.

\section{REFERENCES}

Braak, T., J. F. Cajo and P. Smilauer. 2003. Introduction to Canoco. Centre for Biometry, Wageningen University.

Chiduwa, G., M. Chimonyo and T.E. Halimani. 2008. Herd dynamic and contribution of indigenous pigs to the livelihood of rural farmers in a semi arid area of Zimbabwe. Trop. Anim.Health Prod. 40: 125-136.

Conroy, C.. 2005. Participatory livestock research; a Guide. ITDG publishing. Warwickshire. UK.

Davidson, I. and S.S. Ravi. 2005. Agglomerative Hierarchical Clustering with Constraints: Theoritical and Emperical Results. University of Albany. New York. 12222.

Deka, R., W. Thorpe, M. L. Lapar and A. Kumar. 2007. Assam's pig sub sector: current status, constraints and opportunities. ILRI. New Delhi. India.

Gaspar, P., F.J. Mesias, M. Escribano, A. Rodríguez de Ledesma, and F. Pulidilo. 2007. Economic and Management Characterization of Dahesa Faros; Implication for their sustainability. Agroforestry System. 71:151-162

Gatenby, R. M., and P. B. Chemjong. 1992. Reproduction of pigs in the hills of Eastern Nepal. Trop. Anim. Health Prod. 24:135142.

Hall, S. G. J. 1989. Pig structures of rare pigs: implication for conservation of Backshire, Tamworth, Middle White, Large Black, Gloucester Old Spot, British Saddleback, and British Lop. Conservation Biology. 3 (1):30-38.

Harris, R.J.. 2001. A primer of multivariate statistic. Third Edition. Lawrence Erlbaum Associates, Mahwah Publisher. Mahwah
New Jersey. London.

Ho, R. 2006. Handbook of Univariate and Multivariate Data Analysis and Interpretation with SPSS. Chapman and Hall/CRC. Taylor and Francis Group. Australia.

Iyai, D. A.. 2008. Innovation possibilities in pig keeping systems in Manokwari, Papua Barat province-Indonesia. Thesis. Wageningen University. The Netherlands.

Lanada, E. B., J.-A. L.M. Lee, S. J. Moore, B. S. Chotiw-an and A. A. Taveros, 2005. A Longitudinal Study of Growing Pigs Raised by Smallholder Farmers in The Philippines. J. Preventive Vet.Med. 70:75-93.

Lee, J.-A. L.M., E. B. Lenada, S. J. Moore, B. S. Chotiw-an and A. A. Taveros. 2005. A Longitudinal Study of Sows and Boars Raised by Smallholder Farmers in The Philippines. J. Preventive Vet. Med. 70:95113

Lemke, U., B. Kaufmann, L.T. Thuy, K. Emrich, and A. Valle Zarate. 2008. Evaluation of smallholder pig production systems in North Vietnam: pig production management and pig performances. Livestock Sci. 105:229-243.

Moore, S. J., J.-A. L.M. Lee, E. B. Lanada, B. S. Chotiw-an and A. A. Taveros. 2005. A Longitudinal Study of Unweaned Piglets Raised by Smallholder Farmers in The Philippines. J. Preventive Vet. Med. 70:115131

Nakai, S. 2008. Reproductive performance analysis of native pig smallholders in the hillside of Northern Thailand. Trop. Anim. Health Prod. 37:501-511

Peters, D., N. T. Tinh, M. T. Hoan, and N. T. Yen. 2006. Rural income generation through improving crop-based pig production systems in Vietnam: diagnostics, interventions, and dissemination. Agriculture and human value. 22: 78-85.

Smital, J. 2009. Effects influencing boars semen. Anim. Reproduction Sci. 110:335-346

Smith, L. I. 2002. A Tutorial on Principal Component Analysis. Cornell University. USA.

Taveros, A. and S. J. Moore. 2001. A field trial of the effect of improved piglet management on smallholder sow productivity in the Phillipines. J. Preventive Vet. Med. 49:235247

Wabacha, J.K., J.M. Maribei, C.M. Mulei, M.N. 
Kyule, K.H. Zessin, and W. Oluoch-Kusura, 2004. Characterisation of smallhoder pig production in Kikuyu Division, Central Kenya. J. Preventive Vet. Med. 63 :183-195
XLstat. 2009. XLstat Version 2009.1.02. Microsoft Excel@. Copyright Addinsoft 1995-2009. 